\title{
Sistem Pendukung Keputusan Promosi Kenaikan Jabatan dengan Fuzzy AHP di STMIK STIKOM Indonesia
}

\author{
Putu Sugiartawan $^{1}$, Didit Suprihanto ${ }^{2}$ \\ ${ }^{1}$ Teknik Informatika, STMIK STIKOM Indonesia, Bali, Indonesia \\ ${ }^{2}$ Teknik Elektro, Universitas Mulawarman, Kalimantan Timur, Indonesia \\ e-mail: *putu.sugiartawan@stiki-indonesia.ac.id, ${ }^{2}$ didit.suprihanto@ft.unmul.ac.id
}

\begin{abstract}
Abstrak
Karyawan yang ditempatkan sesuai dengan pengetahuan, keterampilan dan kemampuannya cenderung memiliki motivasi yang tinggi, maka kinerja yang dihasilkan juga akan meningkat. Untuk menjamin orang atau karyawan yang tepat dalam menempati posisi yang tepat juga, seleksi karyawan selalu menjadi hal bagian yang sangat penting pada organisasi perusahaan, khususnya pada sekolah tinggi. proses pengambilan keputusan untuk promosi kenaikan jabatan dapat diselesaikan dengan sistem pendukung keputusan yang digunakan oleh manajer sebagai salah satu dukungan informasi dalam menyelesaikan permasalahan untuk mengisi jabatan, dimana fungsi kinerjanya dapat menghitung pertimbangan setiap kompetensi yang dimiliki masing-masing SDM. SPK dapat memberikan alternatif solusi bila seseorang atau sekelompok orang sulit dalam menentukan keputusan yang tepat dan sesuai. SPK tidak untuk menggantikan fungsi pengambil keputusan dalam membuat keputusan, melainkan hanyalah sebagai alat bantu pengambil keputusan dalam melaksanakan tugasnya. Metode Fuzzy AHP mampu menentukan bobot dengan nilai perbandingan masing-masing kriteria, dan model ini Metode Fuzzy-AHP dapat menutupi keterbatasan metode AHP, yaitu ketidak presisian dalam mengatasi Multi criteria decision making yang memiliki kriteria yang bersifat subjektif. Dengan pendekatan metode tersebut didapat perankingan hasil penentuan jabatan yang sesuai dengan preferensi dari decision maker.
\end{abstract}

Kata kunci-Fuzzy-AHP, promosii Jabatan, SPK

\begin{abstract}
Employees who are placed according to their knowledge, skills and abilities tend to have high motivation, so the resulting performance will also increase. To ensure the right person or employee in the right position too, employee selection has always been a very important part of the company organization, especially in high schools. The decision-making process for promotion of promotion can be completed with a decision support system used by managers as a support for information in solving problems to fill positions, where the performance function can calculate the consideration of each competency possessed by each HR. DSS can provide alternative solutions when a person or group of people is difficult to make the right and appropriate decision. DSS is not to replace the function of decision makers in making decisions, but only as a tool for decision makers in carrying out their duties. Fuzzy AHP method is able to determine the weight with the comparison value of each criterion, and this model Fuzzy-AHP method can cover the limitations of the AHP method, namely imprecision in overcoming Multi criteria decision making which has subjective criteria. With this method approach, the ranking
\end{abstract}

Received May $1^{\text {st }}$ 2020; Revised May 25 ${ }^{\text {th }}$, 2020; Accepted June 10 ${ }^{\text {th }}, 2020$ 
results of the determination of the position are obtained in accordance with the preferences of the decision maker.

Keywords - Fuzzy-AHP, job promotion, DSS

\section{PENDAHULUAN}

Sumber daya manusia di dalam suatu organisasi perusahaan merupakan hal yang sangat

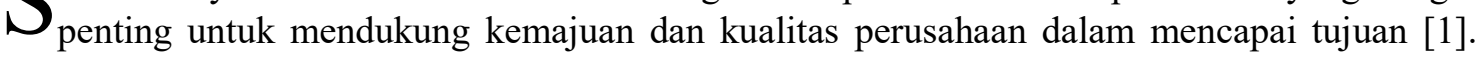
Karyawan yang ditempatkan sesuai dengan pengetahuan, keterampilan dan kemampuannya cenderung memiliki motivasi yang tinggi, maka kinerja yang dihasilkan juga akan meningkat [2]. Untuk menjamin orang atau karyawan yang tepat dalam menempati posisi yang tepat juga, seleksi karyawan selalu menjadi hal bagian yang sangat penting pada organisasi perusahaan [3]. STMIK STIKOM Indonesia merupakan institusi pendidikan yang berfokus kepada pendidikan ilmu berbasis komputer yang memiliki dua program studi yaitu Sistem Komputer dan Teknik Informatika. Didirikan pada tanggal 18 April 2008 dan berada di bawah pengelolaan Yayasan Wahana Widya Wisesa Denpasar.

Pengembangan dan peningkatan pada sistem yang sudah terkomputerisasi tidak hanya difokuskan kepada peroses akademiknya saja, tetapi secara lebih luas perlu adanya sistem pengelolaan secara terkomputerisasi untuk organisasi kampus, dalam hal ini berkaitan dengan penentuan penempatan jabatan yang sesuai dengan kebutuhan organisasi tersebut. Adapun permasalahan yang terjadi, yakni sulitnya menentukan orang yang tepat untuk menduduki jabatan tertentu sesuai dengan apa yang dibutuhkan oleh organisasi kampus, dengan banyaknya kandidat yang memiliki nilai kriteria-kriteria yang hampir sama. Pada saat seleksi jenjang karir atau promosi jabatan hanya dinilai berdasarkan beberapa kriteria saja seperti lamanya mengabdi, kedisiplinan dan prestasi kerja orang yang akan dipromosikan, sehingga terkadang promosi jabatan yang diberikan tidak sesuai kebutuhan kampus, serta salah sasaran dalam pemilihan kandidat dengan kinerja yang baik. Ditentukannya suatu kriteria-kriteria dalam penempatan tugas karyawan tidak terlepas dari tujuan agar karyawan yang akan dipindahkan memenuhi kriteria yang telah ditetapkan [4]. Analisis jabatan merupakan bentuk pengembangan uraian terperinci dari tugas-tugas yang harus dilakukan dalam suatu jabatan, penentuan hubungan dari satu jabatan dengan jabatan lain yang ada, dan penentuan tentang pengetahuan, ketrampilan, dan kemampuan- kemampuan lain yang diperlukan karyawan untuk melakukan pekerjaan secara efisien dan efektif [5].

Dari penjelasan diatas dapat dibuatkan solusi, dengan dibangunnya sebuah sistem yang sudah terkomputerisasi untuk penentuan promosi jabatan yang kosong sesuai dengan keperluan kampus. Kemudian menurut [6], proses pengambilan keputusan untuk promosi kenaikan jabatan dapat diselesaikan dengan sistem pendukung keputusan yang digunakan oleh manajer sebagai salah satu dukungan informasi dalam menyelesaikan permasalahan untuk mengisi jabatan, dimana fungsi kinerjanya dapat menghitung pertimbangan setiap kompetensi yang dimiliki masing-masing SDM. SPK dapat memberikan alternatif solusi bila seseorang atau sekelompok orang sulit dalam menentukan keputusan yang tepat dan sesuai [7]. SPK tidak untuk menggantikan fungsi pengambil keputusan dalam membuat keputusan, melainkan hanyalah sebagai alat bantu pengambil keputusan dalam melaksanakan tugasnya [8]. Salah satu contoh yang akan disorot dalam hal ini adalah cara pemilihan karyawan yang sesuai dengan kriteria yang ada pada suatu jabatan tertentu, maka seandainya terdapat suatu jabatan pada bagian dari perusahaan membutuhkan karyawan, maka dalam hal ini yang bertugas untuk melakukan analisis terhadap karyawan-karyawan yang menurut perhitungan cocok dengan kriteria jabatan tersebut, istilah tersebut disebut analisis kompetensi [9]. Dalam proses AHP secara garis besar merupakan proses membandingkan antara kompetensi individu kedalam kompetensi jabatan,

JSIKTI Vol. 2, No. 5, June 2020: $41-50$ 
semakin kecil gap yang dihasilkan maka bobot nilainya semakin besar yang berarti memiliki peluang lebih besar untuk karyawan menempati posisi tersebut [10]. Untuk menganalisis karyawan yang sesuai dengan jabatan tertentu dilakukan dengan metode AHP, dimana dalam proses ini terlebih dahulu menentukan kompetensi (kemampuan) yang diperlukan oleh suatu jabatan [11].

Metode ini digunakan karena paling sesuai untuk mengambil keputusan yang berhubungan dengan nilai prestasi, dan untuk membandingkan antar kompetensi individu ke dalam kompetensi suatu jabatan [12]. Sedangkan menurut [13], Metode ini dipilih karena mampu menyeleksi kandidat terbaik dari sejumlah karyawan yang ada, dalam hal ini kandidat yang dimaksudkan yaitu karyawan yang berhak menduduki jabatan yang tersedia berdasarkan kriteria-kriteria yang ditentukan. Lalu menurut [14], metode ini digunakan dalam penilaian seleksi pemilihan karyawan, yang dapat memberikan penilaian potensi masingmasing kandidat karyawan dengan melakukan perbandingan AHP pribadi karyawan dengan AHP jabatan yang bersangkutan. Core factor dan secondary factor menjadi perhitungan berikutnya dengan memberikan besaran presentase untuk kedua faktor tersebut [15]. Setelah ditentukan hasil Gap dari masing-masing karyawan, maka perlu diperhitungkan ranking kandidatnya. Kriteria yang digunakan untuk penentuan promosi pada penelitian ini yakni K1, K2, K3, K4, K5. Sistem kompetensi ini terdapat pendeskripsian prestasi dan potensi SDM yang sesuai dengan kebutuhan unit kerjanya [16]. Hasil yang diperoleh dengan adanya sistem pendukung keputusan ini diharapkan dapat memudahkan pelaksanaan kaderisasi dan jenjang karir dalam organisasi kampus, serta bertujuan untuk memudahkan proses, penyusunan dan pengenalan target (dalam hal ini orang yang dicalonkan) dalam memudahkan penyusunan jenjang karir dan kaderisasi dari organisasi kampus.

\section{METODE PENELITIAN}

\subsection{Sistem Pendukung Keputusan}

Sistem pendukung keputusan merupakan sebuah sistem yang digunakan untuk mendukung para pengambil keputusan menejerial untuk memperluas kemampuan mereka dalam situasi keputusan semi terstruktur[11]. Sistem pendukung keputusan merupakan alat bagi para pengambil keputusan, namun tidak untuk menggantikan peran penilaian mereka. Sistem pendukung keputusan menerapkan proses update informasi dan analisis metode yang dapat menghasilkan keputusan yang efektif, menguntungkan bagi perusahaan[12]. Sistem pendukung keputusan berbasis kecerdasan buatan dapat melakukan diagnosis berupa pengetahuan, analisa pakar, pengenalan pola, dan lain-lain dalam lingkup berbagai kasus [13].

Komponen-komponen yang digunakan dalam evaluasi dan proses sistem pendukung keputusan[2], meliputi:

1. Sub sistem manajemen data (data management)

Merupakan subsistem yang memasukkan satu database yang berisi database yang relevan dan dikelola oleh perangkat lunak yang disebut database management system (DBMS).

2. Sub sistem manajemen model (model management)

Merupakan paket perangkat lunak yang memasukkan model keuangan, statistik, ilmu manajemen, atau model kuantitatif lainnya yang memberikan kapasitas analitik dan manajemen perangkat lunak yang tepat.

3. Sub sistem antarmuka pengguna (user interface)

Pengguna berkomunikasi dan memerintahkan sistem pendukung keputusan melalui subsistem ini. Para peneliti menegaskan bahwa beberapa kontribusi unik dari sistem pendukung keputusan berasal dari interaksi yang intensif antara komputer dan pembuat keputusan. 
4. Subsistem manajemen knowledge atau manajemen berbasis pengetahuan (knowledgebased sub systems).

Subsistem ini dapat mendukung subsistem lain dan bertindak sebagai suatu komponen independen. Ia memberikan intelegensi untuk memperbesar pengetahuan si pengambil keputusan.

Sistem pendukung keputusan sebagai sekumpulan prosedur berbasis model untuk data pemprosesan dan penilaian untuk membantu para menejer mengambil keputusan. Dia menyatakan bahwa untuk menjadi sukses, sistem tersebut haruslah sederhana, cepat, mudah dikontrol, adaptif, lengkap dengan isu-isu penting, dan mudah berkomunikasi. Sedangkan Moore \& M. G. (1980) dalam Turban et al. (2005) mendefinisikan sistem pendukung keputusan sebagai sistem yang dapat diperluas untuk mampu mendukung analisis ad hoc data dan pemodelan keputusan, berorientasi terhadap perencanaan masa depan, dan digunakan pada interval yang tidak regular dan tak terencana.

Definisi sistem pendukung keputusan menurut Turban \& Boncze menyatakan sistem pendukung keputusan sebagai sistem berbasis komputer yang terdiri dari tiga komponen yang saling berinteraksi: sistem bahasa (mekanisme untuk memberikan komunikasi antar pengguna dan komponen sistem pendukung keputusan yang lain). Sistem pengetahuan (repositori pengetahuan dominan masalah yang ada dalam sistem pendukung keputusan sebagai data atau sebagai prosedur) dan sistem pemrosesan masalah (hubungan antar komponen lainnya terdiri dari satu atau lebih kapasistas manipulasi masalah umum yang diperlukan untuk pengambilan keputusan). Konsep-konsep yang diberikan oleh definisi tersebut sangat penting untuk memahami hubungan sistem pendukung keputusan dengan pengetahuan. Sedangkan keen dalam mendefinisikan sistem pendukung keputusan sebagai produk dari proses perkembangan, dimana pengguna sistem pendukung keputusan, pembangun sistem pendukung keputusan, dan sistem pendukung keputusan itu sendiri mampu mempengaruhi satu sama lain, sehingga terjadi evolusi sistem dan pola penggunaan.

\section{2 Sumber Daya Manusia}

Karyawan atau SDM itu terdiri dari sekumpulan orang yang membuat rencana, rancangan, mengolah hingga menciptakan barang atau jasa, mengawasi mutu, memasarkan produk, mengalokasikan sumber daya finansial, serta merumuskan seluruh strategi dengan menggunakan daya pikir dan daya fisik guna mencapai tujuan utama organisasi . Sumber Daya Manusia (SDM) adalah berupa manusia yang digerakkan dan dipekerjakan dalam sebuah organisasi atau perusahaan sebagai sumber penggerak, pemikir dan perencana untuk mencapai tujuan organisasi itu [11]. Sumber daya manusia (human resources) mengandung dua pengertian. Pertama, sumber daya manusia (SDM) mengandung pengertian usaha kerja atau jasa yang dapat diberikan dalam proses produksi. Dalam hal ini SDM mencerminkan kualitas usaha yang diberikan oleh seseorang dalam waktu tertentu untuk menghasilkan barang dan jasa. Kedua, menyangkut manusia yang mampu bekerja untuk memberikan jasa atau usaha kerja tersebut.

\subsubsection{Perencanaan Sumber Daya Manusia}

Perencanaan sumber daya manusia adalah proses peramalan yang mengkaji kebutuhan sumber daya manusia di masa depan, untuk menjamin tersedianya tenaga kerja dalam jumlah yang cukup dan kompetensi yang sesuai dengan kebutuhan [12]. Kemudian menurut [13] perencanaan SDM adalah langkah-langkah tertentu yang diambil oleh manajemen guna menjamin bahwa organisasi tersedia tenaga kerja yang tepat untuk menduduki berbagai kedudukan, jabatan, dan pekerjaan yang tepat pada waktu yang tepat.

JSIKTI Vol. 2, No. 5, June 2020: $41-50$ 


\subsubsection{Tujuan Perencanaan Sumber Daya Manusia}

Menurut [14], tujuan perencanaan sumber daya manusia adalah agar organisasi dapat mempersiapkan rencana tenaga kerja sehingga organisasi bisa memenuhi kebutuhan tenaga kerjanya secara tepat tidak kekurangan juga tidak berlebihan. Sedangkan menurut [15] tujuan perencanaan SDM adalah untuk menentukan jumlah SDM beserta karakteristiknya masingmasing (usia, pendidikan, keahlian, sifat, dsb.) yang dibutuhkan organisasi untuk mencapai tujuan stratejik, operasional, dan fungsionalnya, adapun tujuan Perencanaan SDM adalah untuk:

1. Menentukan kualitas dan kuantitas karyawan yang akan mengisi semua jabatan dalam organisasi/perusahaan

2. Menjamin tersedianya tenaga kerja masa kini maupun masa depan, sehingga setiap pekerjaan ada yang mengerjakan

3. Menghindari terjadinya kesalahapahaman manajemen dan tumpang tindih dalam pelaksanaan tugas

4. Mempermudah koordinasi, integrasi dan sinkronisasi (KIS) sehingga produktivitas kerja meningkat

5. Menghindari kekurangan atau kelebihan tenaga kerja

6. Menjadi pedoman dalam menetapkan program penarikan, seleksi, pengembangan, kompensasi, pengintegrasian, pemeliharaan, kedisiplinan dan pemberhentian karyawan.

7. Menjadi pedoman dalam pelaksanaan promosi maupun mutasi dan pensiun karyawan

8. Menjadi dasar dalam melakukan penilaian karyawan.

\subsection{Jabatan}

Pengertian jabatan menurut, [15], Jabatan (Job) ialah sekumpulan pekerjaan (Job) yang berisi tugas-tugas yang sama atau berhubungan satu dengan yang lain, dan yang pelaksanaannya meminta kecakapan, pengetahuan, keterampilan dan kemampuan yang juga sama meskipun tersebar di berbagai tempat.

Menurut [15] Analisis Jabatan/Pekerjaan (Job Analysis) adalah suatu kegiatan pengumpulan data/informasi yang menyangkut tentang sesuatu jabatan pekerjaan untuk menetapkan uraian jabatan/pekerjaan dan persyaratan jabatan/pekerjaan. Analisis jabatan merupakan prosedur untuk menetapkan tugas dan tuntutan ketrampilan dari suatu jabatan dan macam personil yang akan dipekerjakan sehingga dapat diketahui baik itu Job Discription,

maupun Job Spesification, Job Perfomance Standart selain Job Evaluation, Joh Enrichment dae Job Enlargenment. Kemudian menurut [16]Dapat dikatakan bahwa analisis jabatan berbasis kompetensi berarti mendeskripsikan suatu jabatan berkaitan dengan kompetensi yang dapat diukur, dapat diobservasi, dan berkaitan dengan perilaku (pengetahuan, keahlian, dan/atau perilaku) sehingga pegawai yang melakukannya harus menunjukkan kualitas untuk dapat mengemban jabatan dengan baik.

\subsection{Analytical Hierarchy Process (AHP)}

Metode Analytical Hierarchy Process (AHP) adalah metode pengambilan keputusan multi kriteria yang dapat mengkombinasikan analisis kualitatif dan analisis kuantitatif [17]. Sedangkan menurut [18] metode AHP adalah metode yang dapat menyelesaikan masalah multi kriteria yang kompleks. Metode AHP digunakan oleh pengambil keputusan untuk memberikan penilaian kepentingan relatif setiap kriteria, kemudian menentukan nilai preferensi setiap alternatif keputusan berdasarkan kriteria masing-masing. Metode AHP dapat melakukan proses identifikasi yang lebih baik, lebih mudah, lebih efisien dalam analisis bobot kriteria dan alternatif. Metode AHP memungkinkan melakukan menggabungan logika untuk suatu data yang bersifat kuantitatif, kualitatif, pengalaman, wawasan, intuisi serta dapat diimplementasikan 
kedalam suatu algoritma. Dengan demikian, memungkinkan para pengambil keputusan untuk menemukan bobot masing-masing kriteria dan tingkat perbandingan alternatif. Menurut Meng (2013) tahapan dalam pemecahan masalah menggunakan metode AHP sebagai berikut:

1. Membentuk struktur hiraki, Struktur hiraki merupakan gambaran umum dalam penentuan masalah dan solusi.

2. Membuat matriks perbandingan

Matriks perbandingan merupakan matriks persegi $A=\left(a_{i j}\right)_{n x n}$ yang meliputi: $a_{i j}>0$, $\mathrm{a}_{\mathrm{ij}}=1 / \mathrm{a}_{\mathrm{ji}}$ dan $\mathrm{a}_{\mathrm{i}}=\mathrm{a}_{\mathrm{j} j}=1$, dimana sering disebut dengan matriks reciprocal. Matriks perbandingan tersebut dapat dilihat pada persamaan (1)

$$
A=\left(\begin{array}{ccc}
a_{11} & K & a_{1 n} \\
M & O & M \\
a_{n 1} & L & a_{n n}
\end{array}\right)=\left(a_{\mathrm{ij}}\right)
$$

Matriks perbandingan menggunakan skala nilai perbandingan 1-9. Pemberian nilai skala perbandingan berdasarkan keadaaan dan skala kuantitatif yang sesuai.

3. Menghitung hasil perkalian masing-masing elemen pada setiap baris $M i$, sesuai dengan persamaan (2).

$$
M i=\prod_{j=1}^{n} a_{i j}
$$

4. Menghitung $\mathrm{n}$ akar pangkat dari $M i$ menggunakan persamaan (3).

$$
\overline{W_{l}}=\sqrt[m]{M i}
$$

5. Jumlah vector $W i=(\overline{W 1}, \overline{W 2}, \ldots, \overline{W n})^{t}$, untuk proses normalisasi dapat dilihat pada persamaan (4).

$$
W i=\frac{\overline{W_{i}}}{\sum_{j=1}^{n} \overline{W_{i}}}
$$

Dengan demikian, nilai $\mathrm{W}=\left(\mathrm{W}^{1}, \mathrm{~W}^{2}, \mathrm{~W}^{3}, \ldots, \mathrm{W}^{\mathrm{n}}\right)^{\mathrm{t}}$ merupakan fitur dari vector matriks.

6. Menurut Saaty (2007) menghitung nilai lamdamax dari matriks dapat dilihat pada persamaan (5).

$$
\lambda \max =\sum_{i=1}^{n} \sum_{j}^{n} a_{i j} W_{j}
$$

7. Tes konsistensi, Proses perhitungan nilai consistency indeks (CI) dapat dilihat pada persamaan (6).

$$
\mathrm{CI}=\frac{(\lambda \text { maks }-\mathrm{n})}{(\mathrm{n}-1)}
$$

8. Menghitung consistency ratio (CR) dapat dilihat pada persamaan (7).

$$
\mathrm{CR}=\frac{\mathrm{CI}}{\mathrm{RI}}
$$

Berdasarkan hasil dari consistency ratio $(\mathrm{CR})$ yang diperoleh, dengan nilai $\mathrm{CR}<0.1$ maka dapat dinyatakan konsisten.

Fuzzy AHP adalah gabungan dari metode AHP dengan pendekatan konsep fuzzy. Fuzzy AHP digunakan untuk menutupi kelemahan yang terdapat pada metode AHP, seperti halnya permasalahan yang terjadi terhadap kriterian yang memiliki sifat subyektif lebih banyak. Di dalam fuzzy AHP skala rasional fuzzy digunakan dalam identifikasi kekuatan relatif dari sebuah kriteria yang bersangkutan. Sehingga sebuah matriks dapat ditentukan dan nilai akhirnya disajikan dalam angka-angka fuzzy. Metode fuzzy AHP adalah metode pendukung keputusan yang sangat populer dan telah handal dalam mengatasi permasalahan dengan mengukur sebuah kriterian secara kualitatif dan kuantitatif.

Berikut ini adalah langkah-langkah dalam menyelesaikan fuzzy AHP [14] :

JSIKTI Vol. 2, No. 5, June 2020: $41-50$ 
1. Membuat struktur hirarki dengan menentukan perbandingan matriks berpasangan antar kriterian dengan skala TFN .

2. Menentukan nilai sintesis fuzzy $(\mathrm{Si})$ prioritas.

3. Menentukan nilai vektor (V) dan nilai ordinat defuzzifikasi (d'). Apabila hasil yang telah diperoleh pada setiap matriks fuzzy adalah M2 $>\mathrm{M} 1(\mathrm{M} 2=(12, \mathrm{~m} 2, \mathrm{u} 2)$ dan $\mathrm{M} 2=($ $11, \mathrm{~m} 1, \mathrm{u} 1))$, maka untuk nilai vektornya.

4. Normalisasi bobot vektor fuzzy (W). Setelah dilakukan normalisasi pada persamaan (6) maka bobot nilai vektor yang ternomalisasi

\section{IMPLEMENTASI DAN HASIL}

Adapun implementasi dari sistem ditunjukan kepada kepala HRD (Human Resource Develepoment) di STMIK STIKOM Indonesia. Kepala HRD pada SPK menjadi Decision Maker dari pengguna sistem. Adapun Kreteria dari SPK promosi jabatan dijabarkan pada Tabel 1.

Table 1 Kriteria promosi jabatan

\begin{tabular}{|l|l|}
\hline Kode Kriteria & Keterangan \\
\hline C1 & Tingkat Pendidikan \\
\hline C2 & Pengalaman \\
\hline C3 & Prestasi Kerja \\
\hline C4 & Disiplin \\
\hline C5 & Loyalitas \\
\hline
\end{tabular}

Alternatif dari promosi jabatan diberikan untuk mengisi kekosongan pada jabatan pembantu ketua 4, yang dijabarkan pada Tabel 2.

Table 2 Alternatif promosi jabatan

\begin{tabular}{|l|l|}
\hline Kode Alternatif & Keterangan \\
\hline A1 & Putu Sugiartawan \\
\hline A2 & Ida Bagus Ary \\
\hline A3 & Indra Pratistha \\
\hline A4 & Arya Wiguna \\
\hline
\end{tabular}

Pada Gambar 1 menunjukan matrik kriteria untuk promosi jabatan, dimana nilai tersebut diberikan oleh DM atau Kepala HRD STMIK STIKOM Indonesia. Dari matrik perbandingan saaaty tersebut di peroleh bobot masing-masing kriteria yang ditunjukan pada Tabel 3,

\begin{tabular}{|c|c|c|c|c|c|}
\hline & Tingkat Pendidikan & Pengalaman & Prestasi Kerja & Disiplin & Loyalitas \\
\hline Tingkat Pendidikan & 1 & 3 & $1 / 3$ & 2 & $1 / 3$ \\
\hline Pengalaman & $1 / 3$ & 1 & 3 & 2 & $1 / 3$ \\
\hline Prestasi Kerja & 3 & $1 / 3$ & 1 & 3 & 2 \\
\hline Disiplin & $1 / 2$ & $1 / 2$ & $1 / 3$ & 1 & 1 \\
\hline Loyalitas & 3 & 3 & $1 / 2$ & 1 & 1 \\
\hline
\end{tabular}

Gambar 1 Perbandingan matrik kriteria promosi jabatan 
Pada Tabel 3 menunjukan bobot kriteria untuk masing-masing kriteria, bobot tertinggi dimiliki oleh kriteria prestasi kerja dengan Loyalitas, sedangkan bobot terendah dimiliki oleh displin sebesar 0,116 .

Table 3 Nilai Bobot Kriteria

\begin{tabular}{|l|l|}
\hline Kode Kriteria & Bobot Kriteria \\
\hline C1 & 0,176 \\
\hline C2 & 0,176 \\
\hline C3 & 0,273 \\
\hline C4 & 0,116 \\
\hline C5 & 0,268 \\
\hline CR & 0,096 \\
\hline
\end{tabular}

Perbandingan alternatif untuk masing-maing kriteria ditunjukan pada Gambar 2. Pada Gambar tersebut menunjukan perbandingan berpasangan untuk kriteria tingkat pendidikan. Hasilnya konsisten dari nilai CR sebesar 0,069.

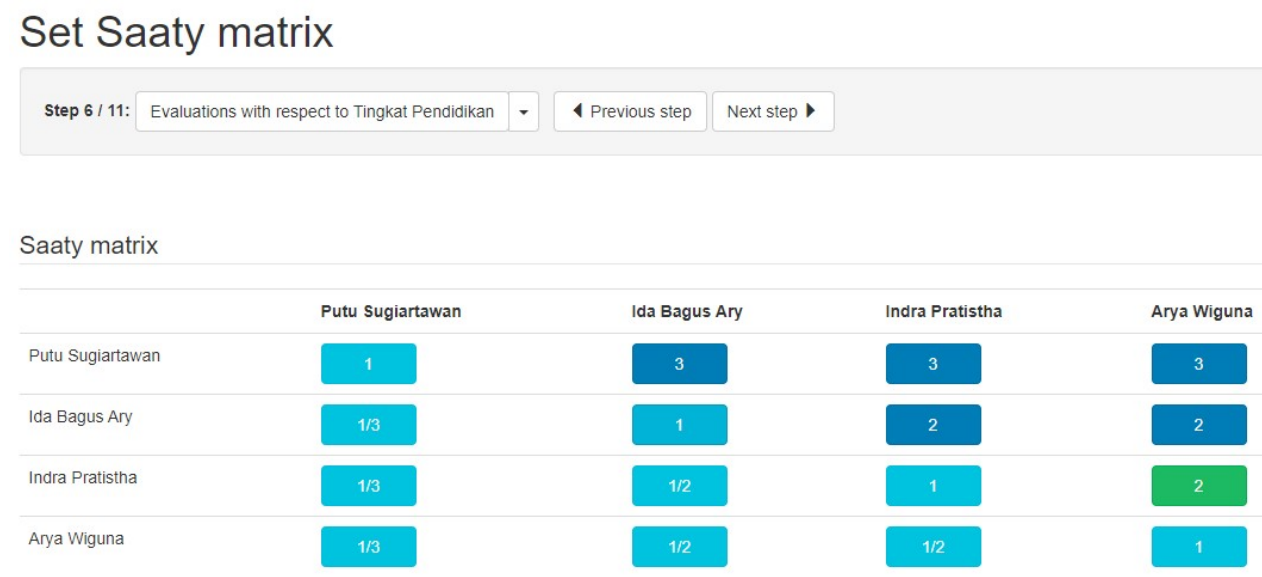

Gambar 2 Perbandingan alternatif pada kriteria tingkat pendidikan

Hasil perbandingan alternatif menghasilkan nilai bobot untuk masing-masing alternatif yang berbeda. Alternatif A1 memperoleh bobot terbesar sebesar 0,49 sedangkan alternatif A4 menghasilkan bobot terkecil sebesar 0,116 .

Pada Tabel 4 menghasilkan dan menunjukan bobot hasil perbandingan alternatif untuk setiap kriterianya. Dan juga nilai konsistensi dari masing-masing perbandingan alternatif tersebut.

Table 4 Hasil perbandingan alternatif

\begin{tabular}{|l|l|l|l|l|l|}
\hline Kode Alternatif & C1 & C2 & C3 & C4 & C5 \\
\hline A1 & 0,49 & 0,276 & 0,276 & 0,49 & 0,439 \\
\hline A2 & 0,231 & 0,478 & 0,478 & 0,231 & 0,311 \\
\hline A3 & 0,163 & 0,144 & 0,144 & 0,163 & 0,146 \\
\hline A4 & 0,116 & 0,102 & 0,102 & 0,116 & 0,104 \\
\hline CR & 0,069 & 0,094 & 0,94 & 0,069 & 0,069 \\
\hline
\end{tabular}

Pada Gambar 3 menunjukan hasil dari fuzzy AHP, dimana diperoleh hasil alternatif A1 menempati posisi pertama dan menjadi pilihan untuk promosi jabatan ke WK 4. Sedangkan Alternatif A3 menempati posisi terkecil atau menjadi pilihan terakhir dari Kepala HRD.

JSIKTI Vol. 2, No. 5, June 2020: $41-50$ 


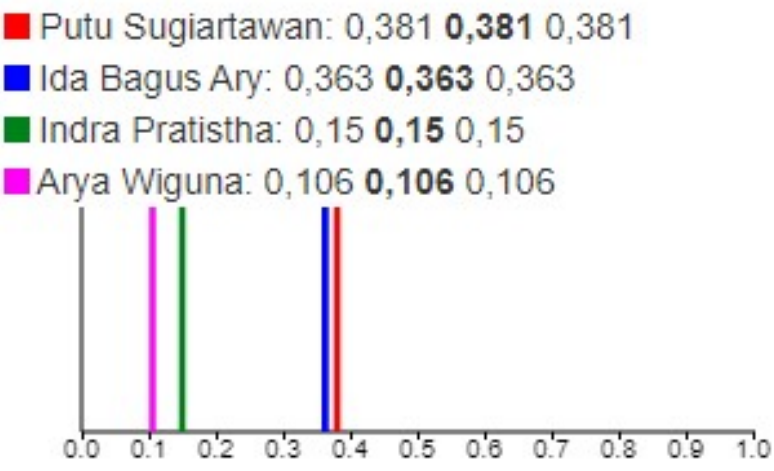

Gambar 3 Hasil Perankingan dengan Fuzzy AHP

\section{KESIMPULAN}

Berdasarkan analisa sistem pendukung keputusan menggunakan model Fuzzy AHP maka dihasilkan sebuah analisa keputusan tingkat akurasi yang tinggi. Hasil evaluasi dan penilaian pegawai berdasakan efektifitas kerja untuk perpanjangan kontrak kerja pada masa periode tertentu. Implementasi SPK dan model secara dinamis maka proses evaluasi dapat dilakukan setiap saat dengan hasil keputusan akhir berupa ranking penilaian yang menjadi rekomendasi kenaikan jabatan di STMIK STIKOM Indonesia. Hasil dari fuzzy AHP menghasilkan alternatif A1 menghasilkan bobot sebesar 0,381 dan Alternatif A3 menghasilkan bobot terkecil yaitu 0,15 .

\section{SARAN}

Saran dan masukan untuk pengembangan penelitian selanjutnya agar dapat mendukung akurasi keputusan yang lebih baik maka penulis mengusulkan untuk menggunakan proses hybrid metode atau perbandingan antar metode dalam lingkup model multi criteri decision making.

\section{DAFTAR PUSTAKA}

[1] S. Wibowo, S. Grandhi, and H. Deng, "Multicriteria Group Decision Making for Selecting Human Resources Management Information Systems Projects," pp. 14051410, 2016.

[2] E. Turban and J. A. Aronson, Decision Support Systems and Intelligent Systems. 2005.

[3] S. Chaising, "Application of a Hybrid Multi-Criteria Decision Making Approach for Selecting of Raw Material Supplier for Small and Medium Enterprises," 2017.

[4] A. G. Shmeleva and A. I. Ladynin, "Industrial management decision support system: From design to software," Proc. 2019 IEEE Conf. Russ. Young Res. Electr. Electron. Eng. ElConRus 2019, pp. 1474-1477, 2019.

[5] E. A. Druzhinina, V. G. Nikitaev, and A. N. Pronichev, "Decision Support System with the Use of " HISTOLOGICAL ANALYSIS OF THYROID TUMORS " Knowledge Base," 2019 IEEE Conf. Russ. Young Res. Electr. Electron. Eng., pp. 1276-1278, 2019.

[6] L. G. Rodriguez and E. P. Chavez, "Feature Selection for Job Matching Application using Profile Matching Model," 2019 IEEE 4th Int. Conf. Comput. Commun. Syst., pp. 263-266, 2019. 
[7] L. Tanti, R. Puspasari, and B. Triandi, "Employee Performance Assessment with Profile Matching Method," 2018 6th Int. Conf. Cyber IT Serv. Manag., no. Citsm, pp. 1-6, 2018.

[8] M. B and Sumardi, "Perancangan Aplikasi Multi Criteria Decision Making Dalam Penerimaan Beasiswa Kepada Dosen Studi Lanjut STMIK Balikpapan Menggunakan Metode SAW,” J. Sist. Inf. dan Komput. Terap. Indones., 2018.

[9] Y. Weizhi and W. Wencheng, "Research of the Evaluation and Selection to Human Resource Management Outsourcing Service Provider," 2011.

[10] R. Astriratma, R. Wardoyo, and A. Musdholifah, "SPK Rekomendasi Pemilihan Kandidat Pejabat Struktural Menggunakan Metode Profile Matching (Studi Kasus: Pemerintah Kota Tarakan),” vol. 11, no. 1, pp. 77-88, 2017. 